\title{
GRAMÁTICA E ARGUMENTAÇÃO EM NASCE O POEMA, DE FERREIRA GULLAR
}

\author{
Cláudia Gomes de Albuquerque Hauly (UEL/PG/CAPES)
}

\section{RESUMO}

O presente artigo tem como finalidade decompor os elementos constituintes relacionados à gramática argumentativa, analisando um recorte do texto Nasce o poema, de Ferreira Gullar. Cada gênero textual tem seu próprio estilo e a escolha do poema objetiva instigar um pensamento crítico e reflexivo no leitor. Um dos objetivos da linguagem é a interação entre seus interlocutores e dentro deste aspecto observamos algo singular na língua: a argumentação. A argumentação é usada no dia a dia das pessoas, e a simples escolha de uma palavra pode ser altamente argumentativa. Transmitir informação parece simples, mas transmitir informação com argumentação não é tão fácil assim. Nesse sentido, pretendemos expor questões a respeito da argumentação e da gramática, pois esta é parte também da atividade discursiva. Dessa forma, é imprescindível o conhecimento dos recursos linguísticos, gráficos, discursivos e imagéticos para a construção textual. À luz de alguns teóricos como Ingedore Koch, Irandé Antunes, José Luiz Fiorin, entre outros, pretendemos contribuir com variados enfoques referentes ao texto.

Palavras-chave: Poema. Gramática. Argumentação.

\begin{abstract}
The present article has the purpose to decompose the related elements represented in the argumentative grammar by the review of the poem clipping Nasce o poema from Ferreira Gullar. Each textual gender has its own style and the poem's choice is to foment the critical and reflexive thinking on the reader. One of the language's objectives is the interaction between its interlocutor and in this aspect, something singular can be observed on the language: the argumentation. People daily use the argumentation, and the single choice of a word can be highly argumentative. It seems simple to transmit information, but to do it with argumentation is not easy, as it seems. In this sense, we pretend to present meaningful questions about argumentation and grammar, because this is also a discursive activity. In this way, it is indispensable the knowledge of the follow argumentative resource: linguistic, graphic, discursive and imagistic for the textual construction. To the light of some theorist as Ingedore Koch, Irandré Antunes, among others, we pretend to contribute with several purposes related to the text.
\end{abstract}

Keywords: $\quad$ Poem. Grammar. Argumentation. 


\section{SEMINÁRIO DE PESQUISA EM CIÊNCIAS HUMANAS - SEPECH \\ Humanidades, Estado e desafios didático-científicos \\ Londrina, 27 a 29 de julho de 2016}

\section{INTRODUÇÃO}

A literatura faz parte da língua, nesse sentido, se a argumentação está na língua, o poema alude ao discurso, isto é, o poema é uma forma de discurso. A língua oferece morfemas com valor argumentativo, dessa forma, pode mostrar o sentido argumentativo de um enunciado. Dos gêneros textuais existentes, a escolha do poema foi pelo fato de ele apresentar múltiplas leituras, pois no texto poético cada indivíduo pode ter compreensões únicas e se reconhecer de acordo com a relação que tem com o mundo. $\mathrm{O}$ poema é um gênero que não se constrói apenas com ideias e com palavras escolhidas aleatoriamente, mas se constrói com a disposição dos versos, com a sonoridade e outros elementos que compõem o nascimento de um texto.

Segundo Cortez e Rodrigues (2005, p. 58):

O poema funciona, de fato, como uma caixa de mil ressonâncias, onde pulsam cada fonema, cada palavra, cada frase. Como objetivo estético, haverá normalmente de "singularizar", de estilizar seu recado, para melhor agilizar, explorar, e segurar nossos sentidos.

Sendo assim, o poema pode provocar diferentes sensações e reflexões no leitor. Nasce o poema, de Ferreira Gullar, poeta neoconcretista, traz o percurso do nascimento do poema e revela que ele não se compõe mecanicamente, mas evolui, no tempo e no espaço, recriando situações cotidianas de um passado esquecido.

A respeito dos recursos que serão trabalhados no recorte do poema, alguns podem ser mais enfáticos, como os aspectos gráficos (letra minúscula), imagéticos (disposição dos versos) e linguísticos (dêiticos, aliteração, entre outros), tais recursos revelam a expressividade por meio da linguagem. Segundo Gullar $(2015$, p. 82): “[...] o poeta está, portanto, sempre apoiado na linguagem existente, nas formas em uso: ele não é um inventor da linguagem, mas um recriador de algumas formas".

A gramática faz parte da atividade discursiva e também engloba o conjunto de normas que particularizam a ação de uma língua. Antunes (2014, p. 31) comenta que "[...] não existe ação de linguagem - ação necessariamente textual - que dispense o concurso da gramática". O léxico e os fatores contextuais também fazem parte da ação da linguagem e, sem eles, o êxito interacional poderá ficar prejudicado.

O homem é um ser provido de razão e aspirações, ele constrói juízos de valor, e, de acordo com Koch (1987), não há discurso neutro, todo discurso possui uma intencionalidade, uma ideologia.

A intenção, no caso do poema de Ferreira Gullar, é demonstrar como se dá o nascimento do poema e como suas lembranças incorporam esse nascimento. Nasce $o$ poema encontra-se no livro Barulhos, que Gullar escreveu entre os anos de 1980 e 1987. Em meio às agitações da época, o poema ressurge recordando o significado do encantamento e do silêncio. Mesmo com tantas inquietações políticas e conflitos interiores, surge o silêncio, e com ele, as reflexões. A tentativa de descoberta do nascimento do poema reproduz um fascínio no " eu lírico" que procura encontrar uma resposta em suas lembranças. Para o autor, o poema poderia nascer em qualquer lugar, até mesmo em um pequeno armarinho no Estácio, em meio às xícaras empoeiradas.

Partindo do pressuposto de Ducrot (1991) de que a argumentação está na língua, o valor argumentativo das palavras é o responsável pela orientação do discurso. A 


\section{SEMINÁRIO DE PESQUISA EM CIÊNCIAS HUMANAS - SEPECH \\ Humanidades, Estado e desafios didático-científicos \\ Londrina, 27 a 29 de julho de 2016}

argumentação é própria das palavras e o ato de argumentar nada mais é que do que convencer, utilizando recursos linguístico-argumentativos que fazem parte da formação dos enunciados. A gramática e a argumentação trabalham juntas, pois a língua faz parte delas. Ensinar as regras que constituem o sistema da língua é essencial para que se analise o sentido que as estruturas gramaticais podem dar aos textos, tanto orais quanto escritos. Assimilamos a linguagem como uma atividade que exerce a interação. Nesse aspecto, Antunes (2014, p. 23) comenta: “[...] uma língua, qualquer língua do mundo, é um conjunto de recursos vocais de que as pessoas dispõem para realizar seus objetivos sociocomunicativos em situações de interação com as outras".

A língua faz parte da interação, principalmente, quando há intenção comunicativa em uma circunstância social por dois ou mais falantes. Ainda a respeito da interação social, Koch (1987, p. 19) argumenta que "[...] a interação social por intermédio da língua caracteriza-se, fundamentalmente, pela argumentatividade". Logo, toda língua exibe em sua gramática mecanismos encarregados por designar a força argumentativa dos enunciados, destacando-se entre eles os aspectos gráficos, imagéticos e linguísticos. Estes mecanismos representam um papel de destaque na organização do discurso.

\section{ANÁLISE DO CORPUS}

A seguir identificaremos, nos fragmentos do poema de Gullar, alguns recursos linguísticos, gráficos e imagéticos que ancoram a construção do poema.

\subsection{Recursos Linguísticos}

Os dêiticos são unidades linguísticas de referenciação que podem introduzir objetos de discurso e também retomá-los. Para Martins (2012, p. 99), os dêiticos relacionam " [...] o enunciado com a situação de enunciação, indicando os participantes da comunicação". A subjetividade é explícita no enunciado pelo uso do pronome de primeira pessoa.

O que caracteriza um dêitico, para Cavalcante (2012, p. 127), é a capacidade "[...] de poder identificar a entidade a que ele se refere se soubermos, mais ou menos, quem está enunciando a expressão dêitica e o local ou o tempo em que esse enunciador se encontra". É o que podemos perceber em Nasce o Poema:

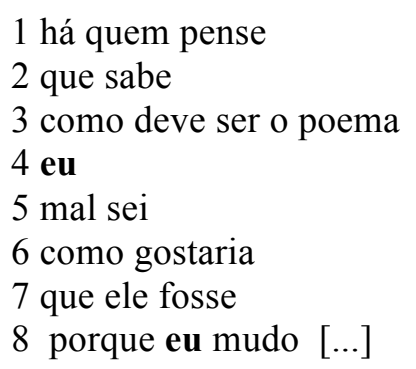

O pronome pessoal reto "eu", que se encontra nos $4^{\circ}$ e $8^{\circ}$ versos do poema, indica o personagem da enunciação, sendo assim, caracteriza-se como dêixis pessoal e 


\section{SEMINÁRIO DE PESQUISA EM CIÊNCIAS HUMANAS - SEPECH \\ Humanidades, Estado e desafios didático-científicos \\ Londrina, 27 a 29 de julho de 2016}

expressa subjetividade ao poema, pois o "eu" lírico mostra-se envolvido emocionalmente no enunciado.

Além da dêixis pessoal, temos também a espacial e a temporal. Segundo Cavalcante (2012, p. 131-132), "[...] a dêixis espacial aponta para informações de lugar, tendo como ponto de referência o local onde ocorre a enunciação", já a dêixis temporal "[...] localiza[m] no tempo do enunciador determinados fatos, isto é, utiliza[m] como ponto de referência o 'agora' da enunciação". O poema é um processo comunicativo que se dirige ao outro e está inserido num determinado contexto espaço-temporal que o artista usa para ver o mundo e posicionar-se perante a realidade que busca representar e transformar em arte.

A seguir, transcrevemos os versos $24^{\circ}$ a $35^{\circ}$ para mostrar os elementos dêiticos:

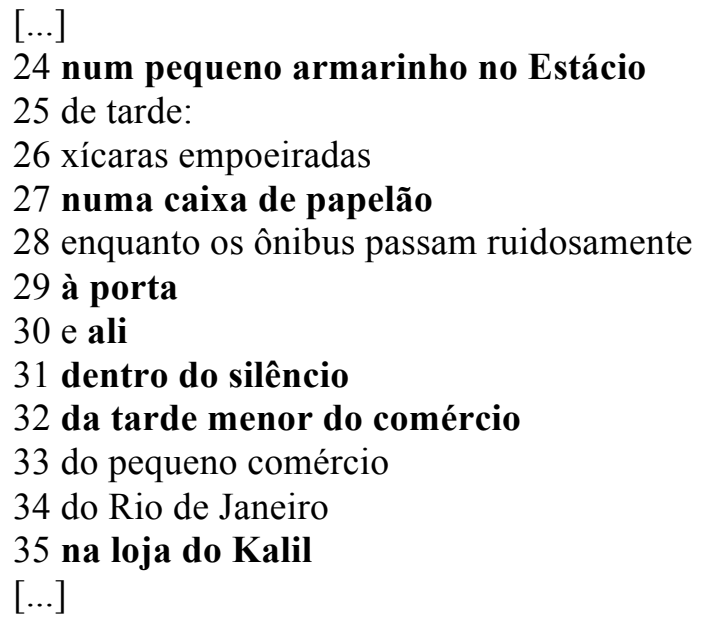

Os dêiticos espaciais sobressaem no poema pela quantidade de locuções adverbiais encontradas. São elas: num pequeno armarinho no Estácio ( $24^{\circ}$ verso), numa caixa de papelão $\left(27^{\circ}\right.$ verso), à porta $\left(29^{\circ}\right.$ verso), o advérbio ali $\left(30^{\circ}\right.$ verso $)$, também faz parte da dêixis espacial, dentro do silêncio / da tarde menor do comércio $\left(31^{\circ}\right.$ e $32^{\circ}$ versos), na loja do Kalil ( $35^{\circ}$ verso). O efeito de sentido do uso dos dêiticos espaciais enfatizam os diferentes locais da enunciação e também a relação de proximidade ocupada pelo locutor. $\mathrm{O}$ "eu" lírico indica que o poema poderia nascer em qualquer lugar.

Nos $12^{\circ}$ e $14^{\circ}$ versos, encontramos a locução adverbial às vezes que se classifica como dêitico temporal.

10 e a poesia irrompe

11 donde menos se espera

12 às vezes

13 cheirando a flor

14 às vezes

15 desatada no olor

O ponto de referência no tempo é representado pela locução adverbial indicando que a frequência da fragrância pode se alternar, ora "cheirando a flor" ora "desatada no olor". 


\section{SEMINÁRIO DE PESQUISA EM CIÊNCIAS HUMANAS - SEPECH \\ Humanidades, Estado e desafios didático-científicos \\ Londrina, 27 a 29 de julho de 2016}

A paronomásia é considerada uma figura de harmonia. Martins (2012, p. 67) sustenta que a paronomásia é '[...] a figura pela qual se aproximam, na frase, palavras que oferecem sonoridade análogas com sentidos diferentes". Sendo persuasivas, as figuras de retórica podem mudar o sentido de uma expressão, de literal para figurado e, desse modo, enriquecer o discurso.

A respeito da paranomásia, Cherubin (1989, p. 51) a define como "[...] figura de harmonia que consiste em reaproximar palavras parônimas, seja por similaridade fônica, seja por um parentesco etimológico ou formal", conforme versos $8^{\circ}$ e $9^{\circ}$ do poema em análise:

\section{8 porque eu mudo}

9 o mundo muda

A fluidez nesse poema pode ser encontrada no jogo entre as formas verbais mudo e muda que se relacionam com o substantivo mundo, aproveitando os valores semânticos dos termos. Mesmo com significados diferentes, intensificam o sentido expresso nos versos.

A estilística analisa os fatores expressivos da língua e preocupa-se com o estilo e com a linguagem afetiva. Segundo Câmara Júnior (1978): "O papel da estilística é depreender todos os processos linguísticos que permitem a atuação da manifestação psíquica e do apelo dentro da linguagem intelectiva". Portanto, para o linguista "a estilística vem complementar a gramática".

Para Fiorin (2014, p.111), a aliteração “[...] é a repetição de fonemas consonânticos ou de traços fônicos consonânticos". De acordo com Sarmento (2006, p. 267) "[...] é a repetição de fonemas iguais ou semelhantes ou palavras próximas, provocando um efeito sonoro sugestivo". A repetição regular de um som consonantal enriquece a qualidade estética e artística do poema.

Nos $8^{\circ}$ e $9^{\circ}$ versos, encontramos a aliteração da consoante nasal bilabial $/ \mathrm{m} /$, em mudo, muda e mundo. A aliteração exerce uma função de construção de ritmos no poema. Além disso, o desencontro dos versos corrobora a noção de movimento buscada pelo "eu lírico". Essa repetição dos fonemas chama a atenção pela expressividade e sonoridade, contribuindo não só para o realce das palavras como também para a harmonia dos sons.

A derivação imprópria consiste, segundo Martins (2012, p. 152), na “[...] substantivação que pode ocorrer com palavras de qualquer classe, por meio de um determinante". Ocorre quando se emprega uma palavra com valor de uma classe gramatical que não é a sua. Para Cunha e Cintra (2001, p. 104), é “ [...]o processo de mudança de classe gramatical de uma palavra sem alteração em sua forma", e ocorre nos seguintes versos:

16 da fruta podre

17 que no podre se abisma

A palavra podre aparece no $16^{\circ}$ verso como adjetivo, já no $17^{\circ}$, a sua classe gramatical é substantivo. Por estar preposicionada, a palavra transforma-se em locução adverbial: no podre, caracterizando deste modo a derivação imprópria e chamando a atenção para a alternância de situações presentes no poema. 


\section{SEMINÁRIO DE PESQUISA EM CIÊNCIAS HUMANAS - SEPECH \\ Humanidades, Estado e desafios didático-científicos \\ Londrina, 27 a 29 de julho de 2016}

\subsection{Recursos Gráficos}

A letra minúscula no início dos versos é considerada um recurso gráfico por quebrar as regras gramaticais. Gullar utiliza-se das características do movimento concreto, limitando também o uso da pontuação. Nesse aspecto, quando o leitor consegue reconhecer as estratégias apresentadas no texto, pode ter uma participação mais crítica e efetiva, pois, além de usar seu conhecimento prévio, estabelece relações de sentido. O conhecimento dos recursos linguísticos contribui no processo de construção discursiva. Para Zilberman e Silva (2005, p. 112-113), o leitor “ [...] colocase como um meio de aproximação entre os indivíduos e a produção cultural, podendo significar a possibilidade concreta de acesso ao conhecimento e agudização do poder de crítica por parte do público".

O poema inicia-se com letra minúscula "há quem pense", quebrando as regras gramaticais. A partir de meados da década de 1920, alguns poetas começaram a experimentar a liberdade nos versos em relação à norma padrão. A minúscula para o poeta funciona como se o poema fizesse parte de uma frase (ou período) que já tivesse começado, antes até do próprio poema, evidenciando a sensação de liberdade do fazer poético.

\subsection{Recursos Visuais}

A disposição espacial do poema resulta de uma experiência concretista de Gullar, que mais tarde é tomada pelo neoconcretismo, recuperando, desse modo, a subjetividade e o regresso da liberdade de experimentação. Os poemas não se agrupam em estrofes, são fragmentados e se espalham pela página, cuja face é o espaço visual.

A espacialidade é um recurso imagético no poema e os poetas neoconcretos consideram a página em branco como o avesso da linguagem. Spanudis (1959) assim se coloca a respeito do assunto:

A espacialização decorre da própria rítmica ou pulsação, não do verso, uma vez que este foi abandonado, mas da vivência poética mesma. É a própria tempórica da vivência poética que se substancializa em espaço vivo [...]. De certo modo podemos dizer que o poema não é simplesmente composto dentro do espaço gráfico aproveitando-se do mesmo para finalidades ópticas-estetizantes, ou hierarquizantes, mas que o espaço gráfico da página (ou o espaço e a forma da placa) é composto, criado, dentro do poema e pelo poema, saindo com isto do seu papel neutro ou passivo, e tornando-se espaço vivo. [...] Gullar com este seu passo libertou a poesia espacial do impasse criado pelos árduos imitadores da pintura abstrata.

E o que observamos no recorte do texto de Ferreira Gullar, Nasce o poema, conforme texto em anexo.

Sobre a poesia neoconcreta, Ferreira Gullar (2015, p. 72-73) comenta:

A página na poesia neoconcreta é a espacialização do tempo verbal: é pausa, silêncio, tempo. Não se trata, evidentemente, de voltar ao conceito de tempo da poesia discursiva, porque enquanto nesta a linguagem flui em sucessão, na poesia neoconcreta a linguagem se abre 


\title{
XI SEMINÁRIO DE PESQUISA EM CIÊNCIAS HUMANAS - SEPECH \\ Humanidades, Estado e desafios didático-científicos \\ Londrina, 27 a 29 de julho de 2016
}

em duração. Consequentemente, ao contrário do concretismo racionalista, que toma a palavra como objeto e a transforma em mero sinal ótico, a poesia neoconcreta devolve-a à sua condição de "verbo", isto é, de modo humano de presentação do real. Na poesia neoconcreta a linguagem não escorre: dura.

O poema agora é um ser temporal e a palavra abre, segundo Gullar (2015,p.72), "[...] a sua complexa natureza significativa". A posição assumida pelo autor acha-se regulada e comprometida com princípios estéticos que o impulsionam a ampliar o seu projeto a cada obra trabalhada.

\section{CONSIDERAÇÕES FINAIS}

Os elementos linguísticos, imagéticos e gráficos contribuem para a construção argumentativa do texto. Nesse sentido, verificamos que não há como desconsiderar a gramática, pois é por meio dela que podemos expandir os conhecimentos e saberes linguísticos. O trabalho de leitura e interpretação de qualquer gênero textual necessita da imersão do leitor em sua análise para tentar compreender as realidades construídas ou reconstruídas por meio dos efeitos de sentido que a gramática oferece. Segundo Koch (1987, p. 21), “[...] o discurso, para ser bem estruturado, deve conter, implícitos ou explícitos, todos os elementos necessários à sua compreensão", obedecendo às situações de evolução e coerência para que o texto seja um texto e não um amontoado de frases.

\section{ANEXO}

Nasce o poema

\author{
1 há quem pense \\ 2 que sabe \\ 3 como deve ser o poema \\ $4 \mathrm{eu}$ \\ 5 mal sei \\ 6 como gostaria \\ 7 que ele fosse \\ 8 porque eu mudo \\ 9 o mundo muda \\ 10 e a poesia irrompe \\ 11 donde menos se espera \\ 12 às vezes \\ 13 cheirando a flor \\ 14 às vezes \\ 15 desatada no olor
}




\section{SEMINÁRIO DE PESQUISA EM CIÊNCIAS HUMANAS - SEPECH \\ Humanidades, Estado e desafios didático-científicos \\ Londrina, 27 a 29 de julho de 2016}

16 da fruta podre

17 que no podre se abisma

18 (quanto mais perto da noite

19 mais grita

20 o aroma)

21 às vezes

22 num moer

23 de silêncio

24 num pequeno armarinho no Estácio

25 de tarde:

26 xicaras empoeiradas

27 numa caixa de papelão

28 enquanto os ônibus passam ruidosamente

29 à porta

30 e ali

31 dentro do silêncio

32 da tarde menor do comércio

33 do pequeno comércio

34 do Rio de Janeiro

35 na loja do Kalil

36 estaria nascendo

37 o poema?

\section{REFERÊNCIAS}

ANTUNES, Irandé. Gramática contextualizada: limpando "o pó das ideias simples". São Paulo: Parábola Editorial, 2014.

CÂMARA JUNIOR, Joaquim Mattoso Contribuição à estilística portuguesa. 3. ed. Rio de Janeiro: Ao Livro Técnico, 1978.

CAVALCANTE, Mônica Magalhães. Os sentidos do texto. São Paulo: Contexto, 2012.

CHERUBIN, Sebastião. Dicionário de figuras de linguagem. São Paulo: Pioneira, 1989.

CORTEZ, Clarice Zamoro; RODRIGUES, Milton Hermes. Operadores de leitura da poesia. In: BONNICI, Thomas; ZOLIN, Lúcia Osana. (Org.). Teoria literária: abordagens históricas em tendências contemporâneas. Maringá: FDUFM, 2005. p. 5873.

CUNHA, Celso; CINTRA, Luís F. Lindley. Nova gramática do português contemporâneo. 3. ed. Rio de Janeiro: Nova Fronteira, 2001.

DUCROT, Oswald. Dire et ne pas dire: principes de sémantique linguistique. 3. ed. Paris: Hermann, 1991. 


\section{SEMINÁRIO DE PESQUISA EM CIÊNCIAS HUMANAS - SEPECH \\ Humanidades, Estado e desafios didático-científicos \\ Londrina, 27 a 29 de julho de 2016}

FIORIN, José Luiz. Figuras de retórica. São Paulo: Contexto, 2014.

GULLAR, Ferreira. Autobiografia poética e outros textos. Belo horizonte: Autêntica, 2015.

, Ferreira. Barulhos (1980-1987). 5. ed. Rio de Janeiro: José Olympio, 2006.

KOCH, Ingedore Grunfeld Villaça. Argumentação e linguagem. 2. ed. São Paulo: Cortez,1987.

MARTINS, Nilce Sant'Anna. Introdução à estilística. 4. ed.rev.2 reimpr.- São Paulo: Edusp, 2012.

SARMENTO, Leila L. Português: leitura, produção, gramática. 2. ed. São Paulo: Moderna, 2006.

SPANUDIS, T. Poesia neoconcreta. Jornal do Brasil, Rio de Janeiro, 22 mar. 1959. Suplemento Dominical.

ZILBERMAN, Regina; SILVA, Ezequiel Theodoro. Pedagogia da leitura: movimento e história. In: SILVA, Ezequiel Theodoro; ZILBERMAN, Regina (Org.). Leitura: perspectivas interdisciplinares. São Paulo: Ática, 2005. p. 111-115. 